\title{
7
}

\section{Arterial Hypertension and Renal Disease}

\author{
Corina Şerban, Rodica Mihăescu, Lavinia Noveanu, \\ Ioana Mozoş, Ruxandra Christodorescu and Simona Drăgan \\ University of Medicine and Pharmacy "Victor Babeş" Timişoara \\ Romania
}

\section{Introduction}

The past decade has witnessed enormous advances in understanding the association between arterial hypertension and renal disease. This chapter aims to provide a comprehensive review about new insights generated from recent experimental and clinical studies that should shed light on the role of the kidney in causing hypertension but also the role of hypertension in causing renal disease. It will focus on pathogenic mechanisms that connect arterial hypertension with target renal damage and new markers able to identify subclinical target-renal damage.

Nowadays, the most important causes of renal failure and dialysis in the world arterial are hypertension and diabetes mellitus. The kidneys have a central role in the control of sodium homeostasis through the important mechanism of regulation of blood pressure. Arterial hypertension is also a well known consequence of chronic kidney disease (CKD), and at the same time one of the main factors causing diabetic and/or non-diabetic chronic renal failure progression (Ljutić, 2003).

Kidneys can be damaged by arterial hypertension by several mechanisms. Because autoregulation of glomerular pressure is impaired in CKD, elevations in systemic blood pressure are associated with increased glomerular capillary pressure. Glomerular hypertension results in increased protein filtration and endothelial damage, causing increased release of cytokines and other soluble mediators, promoting replacement of normal kidney tissue by fibrosis. An important factor contributing to progressive renal disease is activation of the renin-angiotensin system, which tends to increase blood pressure and also promotes cell proliferation, inflammation, and matrix accumulation (Dworkin, 1999). An important part of the standard of care in clinics is the evaluation of microalbuminuria in order to detect renal organ damage that may influence the occurrence of future cardiovascular events. Screening for renal organ damage is part of classification schemes and clinical assessment process and influences the therapy to prevent disease progression and delay or prevent future cardiovascular events. The presence of target organ damage defines a high-risk population that develops complications due to suboptimal disease control or accelerated development and progression of the atherosclerotic process (Lockhart, 2009).

The renin-angiotensin system (RAS) is the most important mechanism for blood pressure regulation and electrolyte homeostasis. It was suggested that the major fraction of angiotensin II present in renal tissues is locally generated from angiotensinogen delivered to 
the kidney as well as from angiotensinogen locally produced by the proximal tubule cells (Kobori, 2007). Renin is produced by the cells of the juxtaglomerular apparatus cells and then delivered in the renal interstitium and vascular compartment resulting local generation of angiotensin. Angiotensin-converting enzyme is abundant in the kidney and is present in the proximal tubules, distal tubules, and collecting ducts (Kobori, 2010). Angiotensin I delivered to the kidney can also be converted to angiotensin II (Komlosi, 2003). All of the components necessary to generate intrarenal angiotensin II are present along the nephron (Navar, 2002; Kobori, 2007). Recently, in the Bogalusa Heart Study was proved that urinary level of angiotensinogen can be a new and potential marker of intrarenal RAS status in kidney disease due to arterial hypertension (Kobori, 2010). An important role in progression of inflammation and fibrosis seems to involve the renin-angiotensin system, and specifically the angiotensin-converting enzyme (ACE)-angiotensin (Ang) $\mathrm{II}_{-} \mathrm{AT}_{1}$ receptor axis. $\mathrm{ACE}_{2}$, a new component of the renin-angiotensin system, has emerged as a key enzyme that selectively degrades Ang II and generates Ang-(1-7), a bioactive peptide with antiinflammatory and anti-fibrotic actions (Chappell, 2010). The deficiency of angiotensinconverting enzyme 2 is associated with elevated tissue and circulating levels of angiotensin II, reduced levels of angiotensin and progressive glomerulosclerosis in the kidneys (Tikellis, 2011). Definitely, the overexpression of angiotensin-converting enzyme 2 may produce adverse cardiac effects, and angiotensin-converting enzyme 2 and its metabolic products may promote epithelial-to-mesenchymal transition (Tikellis, 2011).

Increased activity of the intrarenal RAS is another concept considered responsible for initiating and maintaining an elevated blood pressure in patients with hypertension and it is sustained by a lot of studies (Mitchell, 1992; Navar, 1999; Navar, 2002; Guyenet, 2006; Kobori, 2007).

Since current European guidelines on hypertension (Mancia, 2007), stratify individuals based on both known risk factors and early markers of subclinical target-organ damage, the chapter focuses further on new and old available biomarkers that can detect renal damage in arterial hypertension. Blood urea nitrogen and creatinine clearance are well-established biomarkers of renal function that can be measured cheaply and easily. Reduced glomerular filtration rate (GFR) and increased urinary albumin excretion are manifestations of target organ damage in hypertension. New renal biomarkers include: urinary level of angiotensinogen, plasma aldosterone concentration, hyperhomocysteinemia and cystatin $\mathrm{C}$. Antihypertensive agents like diuretics, angiotensin converting enzyme (ACE) inhibitors, angiotensin II (Ang II) receptor antagonists, B-blockers, or calcium channel blockers (CCBs) can improve end organ damage and effectively reduce hypertension (Cohuet, 2006).

\section{From arterial hypertension to renal organ damage}

The increasing prevalence of arterial hypertension in general population is caused by a sum of factors involved in renal disease progression like atherogenic dyslipidemia, metabolic syndrome, type II diabetes, anemia, and disorders of mineral metabolism.

The first form of hypertension most commonly observed in early or borderline hypertension is characterized by salt-resistance, normal or only slightly decreased GFR, relatively normal or mild renal arteriolosclerosis, and normal renal autoregulation. The patients affected by this form of hypertension are at minimal risk for renal progression.

The second form of hypertension, characterized by salt-sensitivity, renal arteriolar disease, and blunted renal autoregulation, defines a group at highest risk for the development of 
microalbuminuria, albuminuria, and progressive renal disease. This second form is more likely to be observed in blacks, in subjects with gout or hyperuricemia, with low level lead intoxication, or with severe obesity/metabolic syndrome (Johnson, 2005).

Essential hypertension is frequently associated with arteriolar thickening, fibrinoid deposition in the glomeruli, and proteinuria (Cohuet, 2006). The deleterious effects of systemic hypertension on renal vascular bed depend on the degree to which the microcirculation is exposed to elevated pressures. Renal injury occurs when the preglomerular autoregulatory mechanism is insufficient to maintain flow and pressure in the kidney (Griffin, 2003).

Chronic hypertension can lead to nephrosclerosis, a common cause of CKD (Porth, 2011). Clinicians use different terms to identify renal damage caused by hypertension like nephrosclerosis, benign nephrosclerosis, hypertensive kidney disease, or nephroangiosclerosis. Two clinicopathologic patterns have been described until now. The first form is benign nephrosclerosis or simply nephrosclerosis, characterised by microvascular changes with hyalinosis of the preglomerular vessel walls and thickening of the intima and reduplication of the internal elastic lamina of the arcuate and interlobar arteries. These modifications can lead to glomerular damage, glomerulosclerosis, patchy tubular atrophy, and interstitial fibrosis. The second form is malignant nephrosclerosis, associated with accelerated or malignant hypertension, characterized by fibrinoid necrosis and myointimal hyperplasia and left untreated can cause progressive renal insufficiency. It becomes a rare entity today due to improvements of antihypertensive management (Marin, 2005). Brenner established the central role for nephron injury and loss in glomerular hypertension. The remaining nephrons develop glomerular capillary hypertension accompanied with hyperfiltration (Brenner, 1982). Nephrosclerosis has actually been seen as a form of intrarenal renovascular disease (Marín, 2005). Beside benign and malignant nephrosclerosis, the spectrum of hypertension-induced renal damage is larger. The pathogenetic mechanisms involved in hypertensive renal damage seems to be the systemic blood pressure "load", the degree to which such load is transmitted to the renal vascular bed and the local tissue susceptibility to any given degree of barotrauma (Bidani, 2004).

In 2009 was proposed a new theory about nephrosclerosis induced by hypertension that involves the genetic $\mathrm{MYH}_{9}$ polymorphisms. The presence of $\mathrm{MYH}_{9}$ polymorphisms in individuals leads to products that disrupt normal podocyte function, causing podocyte injury, which ultimately leads to glomerulosclerosis (Freedman, 2009). The presence of genetic polymorphisms leading to intrinsic kidney injury suggest that the failure of strict blood-pressure control to prevent CKD progression does not relate to blood pressure alone, but rather relates to factors intrinsic to the kidney that are yet to be defined. In African American Study of Kidney Disease (AASK) could be observed that blood-pressure control alone cannot reverse existing kidney damage or stop progressive kidney damage (AASK) (Appel, 2008).

Tubulointerstitial injury seems to be one of the main histological determinants of hypertension-related kidney damage. This fact is of particular importance because the pathology correlates with the degree and progression of renal impairment, regardless of the type and origin of kidney injury. Long time it was supposed that interstitial and tubular damage is secondary to glomerular and vascular injury and occurs in the final stages of hypertensive nephropathy. However, experimental studies have demonstrated that this type of kidney damage can be present in hypertensive patients before any changes in glomerular vessels (Mai, 1993). Considering the results of these studies, it may be 
hypothesized that the tubulointerstitium may be an initial site of renal injury in primary hypertension. This hypothesis is based only on animal studies, however, and has not been finally confirmed in clinical research (Tylicki, 2003).

Endothelium seems to be at the crossroads of the risk for renal impairment and cardiovascular complications in individuals with essential hypertension, therefore, combined effects of low-grade inflammation, oxidative stress and hyperuricemia may be the link between arterial hypertension and renal organ damage. Different studies showed that endothelial dysfunction is associated with renal function decline in hypertensive patients with normal or only mildly impaired baseline renal function (Perticone, 2010). It is possible that a reduction of GFR could induce endothelial dysfunction, establishing a vicious circle which, if not interrupted, promotes the progression of both renal and vascular damage. Therefore, systemic endothelial dysfunction represents an important physiopathological mechanism for the appearance and progression of mild renal dysfunction in hypertensive status. Interstitial inflammation together with oxidative stress participates to the development and maintenance of hypertension by reducing the number of nephrons, limiting therefore the sodium filtration (Brenner, 1988). Ultimately, these effects lead to end stage renal disease. In hypertension, the permeability of the glomeruli is altered which leads to an excess of protein infiltration. The toxicity of this protein load generates tubular damage, inflammation and scarring (Cohuet, 2006).

Novel biomarkers of renal damage are currently investigated and could be used to identify the first signs of hypertension-associated renal injury. There are a number of definitions of the term "biomarker". In general, they have in common three components:

1. They are objectively measured indicators of specific anatomic, physiologic, biochemical, or molecular events;

2. They are associated with normal biological processes or accompany the onset, progression and/or severity of specific pathological or toxic conditions;

3. They are useful to assess the progress of injury, disease or the effects of therapeutic intervention.

\subsection{Low grade inflammation}

The degree of inflammation and fibrosis of the tubulointerstitial compartment are considered strong predictors of the renal function loss and the risk of progression to endstage renal disease (Leemans, 2009). Tissue fibrosis and chronic inflammation are common causes of progressive renal damage, leading to loss of physiological functions. Renal fibrosis can be defined by the accumulation of interstitial leukocytes and fibroblasts, contributing to abnormal accumulation of extracellular matrix (ECM) and, eventual, tubular atrophy and loss of renal function (Iwano, 2004). Interestingly, the concept of renal inflammation in progressive kidney disease is intertwined with the concept of hemodynamically induced renal injury (Stuveling, 2005). In the last years, low-grade inflammation has acquired progressive recognition as a mechanism facilitating the occurrence of both glomerular and tubulo-interstitial renal damage. Recently, it was shown that Toll-like receptor 2 (TLR2) is expressed in the kidney and activated by endogenous danger signals (Leemans, 2009). The renal fibrosis is considered to be the common final pathway by which kidney diseases with variable etiology progresses to end-stage renal failure. It is therefore important to identify factors that participate in the initiation of tubulointerstitial inflammation and subsequent interstitial fibrosis during progressive renal injury. Toll-like receptor 2 (TLR2) and 4 plays a crucial role in the 
induction of acute inflammation and early tubular injury in the kidney in a reversible model of acute renal injury (Leemans, 2009).

Among inflammatory markers, high-sensitive C-reactive protein levels has been recently associated with early kidney damage and seems to best identify the subgroup of hypertensive patients at risk for renal involvement (Zoccali, 2006). Subtle elevations in plasma concentration of high-sensitive C-reactive protein, a reliable marker of inflammation, were associated with similarly subtle reductions in creatinine clearance in the Prevention of Renal and Vascular Endstage Disease (PREVEND) study (Stuveling, 2003).

\subsection{Oxidative stress}

The role of reactive oxygen species (ROS) has been documented in both experimental and human hypertension (Romero, 1999). It was observed that ROS can have direct and indirect effects on the vascular reactivity (Cohuet, 2006). Indeed, by inactivating endothelial nitric oxide, ROS impair vasodilation and can also have direct effects on vascular tone in function of the quantity of ROS produced and the involved vascular bed. The major ROS is the superoxide anion $\mathrm{O}^{2-}$ and the most common response to its stimulus is vasoconstriction directly or potentiation of the constriction due to angiotensin II (Ang II), thromboxane $\mathrm{A}_{2}$, endothelin-1 (ET-1), and norepinephrine by increasing intracellular calcium in smooth muscle and endothelial cells. In addition, tubulointerstitial inflammation (infiltration and accumulation of lymphocytes and macrophages) appears to be responsible for the mediation of sodium retention in salt-sensitive models of hypertension. Moreover, oxidative stress may have an influence on sodium retention through tubulointerstitial accumulation of Ang IIpositive cells. These 2 mechanisms for hypertension pathogenesis are related by their effects on sodium retention via intrarenal Ang II activity. In the kidney, Ang II decreases glomerular filtration rate, increases tubular sodium reabsorption, and impairs pressurenatriuresis contributing to renal insufficiency. Additionally, oxidative stress has proinflammatory effects: firstly, it activates NF-kB, a transcription factor for proinflammatory genes, which promotes leucocytes infiltration by increasing the expression of adhesion molecules and secondly, it induces the expression of heat shock proteins, resulting in cell death and apoptosis in an inflammatory environment.

\subsection{Hyperuricemia}

Uric acid may mediate aspects of the relationship between hypertension and kidney disease via renal vasoconstriction and systemic hypertension (Weiner, 2008). Hyperuricemia is present in $25-40 \%$ of untreated hypertensive individuals, in $50 \%$ of those treated with diuretics, and in over $80 \%$ of those with malignant hypertension and is associated with cardiovascular disease, but is not clear if it is an independent risk factor or just a marker associated with cardiovascular risk factors like insulin resistance, obesity and arterial hypertension (Feig, 2008). The high serum uric acid levels in hypertension have been attributed to several mechanisms:

1. The reduced renal blood flow that often accompanies the hypertensive state stimulates urate reabsorption in the proximal tubule;

2. The hypertensive microvascular disease leads to local tissue ischemia, the release of lactate that blocks urate secretion in the proximal tubule and increases uric acid synthesis. Tissue ischemia leads to ATP degradation to adenosine and xanthine oxidase. Both increased xanthine and xanthine oxidase result in increased generation of uric acid and oxidant $\left(\mathrm{O}^{2-}\right)$ formation; 
3. Additional factors can contribute to hyperuricemia in hypertension such as alcohol abuse, lead intoxication, and diuretic use.

Animal model studies have shown that hyperuricemia activates the renin-angiotensin system, induces oxidative stress and reduces renal function. In experimental rat models of hypertension it was shown that hyperuricemia is associated with renal vasoconstriction and is positively correlated with plasma renin activity, these data suggest that uric acid may have adverse effects that are mediated by activated RAS (Lee, 2006). Few studies demonstrated an association between hyperuricemia and microalbuminuria in hypertensive patients (Viazzi, 2007). Recent studies proved that hyperuricemia predicts the development of new-onset kidney disease (Obermayr, 2008) and is considered a risk factor for the development and progression of renal disease (Kang, 2002; Johnson, 2005; Nagakawa, 2006; Feig, 2009).

\section{From chronic kidney disease to arterial hypertension}

Although the relationship between hypertension and CKD has been recognized for several hundred years, the prevalence of CKD among patients with normal blood pressure has not been assessed in randomly sampled populations. Crews et al reported recently that $13.4 \%$ of people who have normal blood pressure have CKD (Agarwal, 2010).

From a clinical point of view, kidney diseases can be classified into two categories according to the onset of the renal pathology (but irrespective of the etiology of injury): (i) Acute kidney injury (AKI) and (ii) Chronic kidney disease (CKD).

AKI, also known as acute renal failure or acute kidney failure, is a rapid loss of renal function, with variable evolution (full, partial or no recovery of a normal renal function), resulting in failure of urinary elimination of nitrogenous waste products (urea nitrogen and creatinine). This impairment of renal function results in elevations of blood urea nitrogen and serum creatinine concentrations. While there is no disagreement about the general definition of ARF, there are substantial differences in diagnosis criteria of ARF (eg, magnitude of rise of serum creatinine concentration). From a clinical perspective, for persons with normal renal function and serum creatinine concentration, GFR must be dramatically reduced to result in even modest increments (eg, 0.1 to $0.3 \mathrm{mg} / \mathrm{dL}$ ) in serum creatinine concentration (Dwinnell, 1999).

AKI and CKD affect patients worldwide and both are associated with a high morbidity and mortality rate (Prunotto, 2011). AKI community-based incidence has increased by $60 \%$ in the past few years, affecting up to $15.3 \%$ of all hospitalized patients. CKD is a major public health problem throughout the world. CKD affects more than $13 \%$ of the population in the USA and in Europe (Prunotto, 2011). The worldwide impact of CKD is significant, yet underestimated. According to the World Health Report 2002 and the global burden of disease project, kidney and urinary tract diseases contribute to 850,000 deaths per year and 15,010,167 in disability-adjusted life years (Staples, 2010).

Chronic kidney failure, also known as chronic renal failure, chronic renal disease, or chronic kidney disease, is a slow progressive loss of kidney function over a period of several years. The definition of CKD is kidney damage or a GFR below $60 \mathrm{~mL}$ per minute per $1.73 \mathrm{~m}^{2}$ for three months or more (National Kidney Foundation, 2004). It has been appreciated for several decades that once GFR has decreased below a critical level, CKD tends to progress relentlessly toward ESRD (Taal, 2006). Earlier recognition of CKD could slow progression, prevent complications, and reduce cardiovascular-related outcomes (Plantinga, 2010). Due 
to the asymptomatic nature of this disease, CKD is not frequently detected until its later progress, resulting in loss of prevention opportunities. Progress to kidney failure or other adverse outcomes could be prevented or delayed through early detection and treatment of CKD (Locatelli, 2002).

Until now the available literature exploring the epidemiology of CKD overall has not classified individuals according to the underlying etiology. Rather, the available population cohort data gathered via NHANES and the national Kidney Foundation's KEEP have provided information on comorbid conditions associated with CKD, including hypertension, as opposed to providing accurate estimates of CKD resulting from hypertension; as a result, only estimates of CKD associated with hypertension can be provided. The 2010 USRDS report summarizes the NHANES data on CKD and comorbid conditions. Compared to individuals without CKD, individuals with any stage of CKD (stages 1-5) have higher rates of hypertension (Udani, 2011). The strong association of hypertension with CKD was confirmed by data from KEEP. However, the KEEP data suggest that hypertension is more prevalent at early stages of CKD and that individuals with CKD have even higher rates of hypertension than NHANES data suggest. The KEEP investigators found that the overall prevalence of hypertension exceeded $50 \%$ in all individuals with CKD, regardless of GFR, and in those with 'normal' renal function (GFR $>100 \mathrm{ml} / \mathrm{min} / 1.73 \mathrm{~m}^{2}$ ) the prevalence of hypertension was $57 \%$. The two databases, however, included different methods of sampling individuals and, overall, have different demographical data (Udani, 2011).

The attention paid globally to CKD is attributable to five factors: the rapid increase in its prevalence, the enormous cost of treatment, recent data indicating that overt disease is the tip of an iceberg of covert disease, an appreciation of its major role in increasing the risk of cardiovascular disease, and the discovery of effective measures to prevent its progression (Barsoum, 2006). Furthermore, a gender-different prevalence of CKD was revealed in most included studies. Females had a higher prevalence of CKD than males. Females have less muscle mass as compared to males and the muscle mass is a major determinant of serum creatinine concentration (Heimsfiled, 1983).

Hypertension is present in more than $80 \%$ of patients with CKD and contributes to progression of kidney disease toward end stage (ESRD) as well as to cardiovascular events such as heart attack and stroke (Toto, 2005). In fact the risk for cardiovascular death in this patient population is greater than the risk for progression to ESRD. Proteinuria is an important co-morbidity in hypertensive patients with CKD and increases the risk of disease progression and cardiovascular events.

\subsection{Pathogenesis}

Hypertension has long been recognized as a consequence of renal impairment and an important factor in the progression of CKD. The RAS together with genetic background, renal anemia, altered mineral homeostasis, atherogenic dyslipidemia, chronic inflammation, and oxidative stress and others cardiovascular risk factors such as diabetes, smoking, and obesity are the main contributors in the pathogenesis (Wühl, 2008). CKD pathogenesis is characterized by a progressive loss of renal function, and an excessive deposition of extracellular matrix in the glomeruli and tubular interstitium (López-Novoa, 2011). Chronic glomerulonephritis and interstitial nephritis are currently the principal causes of CKD in developing countries, reflecting the high prevalence of bacterial, viral, and parasitic infections affecting the kidneys (Barsoum, 2006). 


\subsection{Hyperuricemia}

Hyperuricemia is highly prevalent in patients with CKD, reflecting reduced efficiency in renal excretion of uric acid associated with hypouricosuria. Evaluating the role of uric acid in the development or progression of CKD is difficult due to the number of confounders to any study (Feig, 2009). A decline in GFR is associated with increased values of serum uric acid because uric acid is predominantly cleared by the kidneys (Marangella, 2005). The role of uric acid in the initiation and progression of CKD remains controversial. Recent epidemiological and experimental evidence suggested that uric acid might be involved in the development of CKD. In animal studies, experimental hyperuricemia is associated with increasing proteinuria, impaired renal function, glomerulosclerosis, renal interstitial fibrosis and preglomerular vasculopathy (Kang, 2002). Increased renal renin expression appears to be involved in these adverse effects of uric acid on renal function. In humans, hyperuricemia also appears to be associated with activation of the intrarenal RAS (Kobori, 2007). In the Cardiovascular Health Study, SUA levels did not predict incident CKD but were independently associated with the progression of pre-existing CKD (Tziomalos, 2010).

\subsection{Assessment of kidney function}

Blood urea nitrogen and creatinine clearance are well-established biomarkers of kidney function that can be measured cheaply and easily (Tesch, 2010). Increases levels of serum creatinine are the main manifestations of hypertension-associated renal dysfunction. Persistent increases of serum creatinine levels reflect an important renal parenchymal damage and some degree of irreversible kidney dysfunction (Udani, 2011). CKD from glomerular disease associated with arterial hypertension can be detected by markers of renal parenchymal disease, like proteinuria. The evidence of early kidney injury is elusive without overt glomerular disease that can be found in hypertensive nephrosclerosis or early diabetic nephropathy. The diagnosis and staging of CKD is nowadays based upon the presence of signs of kidney damage together with the estimation of the GFR (Montañés, 2011).

\subsubsection{Albuminuria}

Albumin is the most abundant protein in the circulation and during normal kidney function very little intact albumin is excreted by the kidney ( $<30 \mathrm{mg} /$ day in humans) (Tesch, 2010). It is known that a slight increase of urinary albumin excretion (microalbuminuria) is a predictor of renal and cardiovascular events in hypertensive patients (Hillege, 2002). Albuminuria is frequently used as an early marker of renal injury because it often precedes a decline in renal function (Tesch, 2010). In arterial hypertension, an increased transglomerular passage of albumin may result from several mechanisms-hyperfiltration, glomerular basal membrane abnormalities, endothelial dysfunction, and nephrosclerosis (Redon, 2002). Microalbuminuria can also be considered a marker of underlying generalized endothelial or vascular dysfunction. The presence of a single measurement microalbuminuria does not confirm the presence of glomerular disease or parenchymal kidney injury (Udani, 2011). A 2010 debate questioned the relevance of microalbuminuria measurements in the diagnosis of kidney disease and controversies regarding its use as a marker of CKD still exist. The results of the Avoiding Cardiovascular events through Combination therapy in Patients living with systolic Hypertension (ACCOMPLISH) study highlights the limits of microalbuminuria as a marker of kidney disease and predictor of CKD progression (Jamerson, 2004). 


\subsubsection{Serum creatinine and estimated glomerular filtration rate}

In clinical practice, serum creatinine became the almost universal biomarker of choice for GFR (Dalton, 2010). Now it appears to be a rather unreliable marker of GRF because creatinine serum concentrations are affected by tubular secretion, age, sex, muscle mass, physical activity, and diet, and therefore creatinine does not have a direct relationship with the GFR (Hsu, 2002). The Cockcroft-Gault and the Modification of Diet in Renal Disease (MDRD) equations, both based on serum creatinine, are being used increasingly because they overcome, at least in part, some of the limitations of creatinine measurements (Cockcroft, 1976; Levey, 1999). Both equations are currently recommended for the estimation of GFR, which is an established method for detection and classification of CKD in clinical practice (National Kidney Foundation, 2002). The development of formula for estimating GFR and disease staging based on serum creatinine reiterate the continuing importance of this biomarker (Dalton, 2010).

\subsubsection{Urinalysis}

Urinalysis is considered the major noninvasive diagnostic tool available to the clinician. Although examination of the urine can also provide some information about disease severity, such a direct relationship between the urinalysis and disease severity is not always present (Post, 2006). A normalization of the urinalysis in patients with acute glomerulonephritis can be considered the resolution of the active inflammatory process, a recovery or healing with irreversible glomerular scarring and nephron loss. In this setting, repeated renal biopsy may be required to accurately estimate the status of the renal disease. Despite potential limitations, a complete urinalysis should be performed in all patients with renal disease (Post, 2003).

\subsubsection{Aldosterone}

Aldosterone, the main mineralocorticoid synthesized by the adrenal gland, has an essential function in sodium and water homeostasis and urinary excretion of potassium (Roldán, 2010). It is an important mediator of collagen turnover, stimulating the expression of various profibrotic molecules and inhibiting other antifibrotic molecules, thereby assuming a decisive role in the development of renal fibrosis. Aldosterone also has an important pathogenic role in hypertension and vascular remodeling, in left ventricular hypertrophy, and in renal disease, specifically proteinuria and glomerulosclerosis in patients with hypertension (Roldán, 2010). A lot of experimental studies analysed the damage caused by aldosterone in the mesangium, basement membrane, and renal tubule and indicated an important pathologic role of the hormone in renal function impairment. The contribution of aldosterone to the development of arterial hypertension in the general population has been shown recently by the Framingham Offspring Study in which serum plasma aldosterone levels in normotensive subjects predicted subsequent increases in blood pressure and in the development of incident hypertension (Vasan, 2004). Plasma aldosterone concentration can be used as a marker of impaired renal function in the initial phases of arterial hypertension (Roldán, 2010).

\subsubsection{Hyperhomocysteinemia}

Another marker of renal damage is hyperhomocysteinemia. Serum homocysteine concentrations are significantly elevated in patients with albuminuria and low GFR 
(Ikeyaga, 2005). In the Horn study, high plasma homocysteine was associated with microalbuminuria independently of other risk factors (Hoogeveen, 1998). Several biochemical mechanisms have been proposed to explain the presumed vasculotoxic effects of homocysteine. The main theory is that high homocysteine levels lead to endothelial dysfunction. Impaired endothelial vasomotor responses have been ascribed to a reduced bioavailability of nitric oxide due to auto-oxidation of homocysteine in plasma which leads to oxidative inactivation of nitric oxide (Welch, 1998). Alternatively, homocysteine may lead to the accumulation of asymmetric dimethylarginine by inhibiting its catabolizing enzyme dimethylarginine dimethylaminohydrolase (van Guldener, 2006). Hyperhomocysteinemia could cause subclinical renal interstitial injury, and reduced renal function promotes further rise in plasma homocysteine (Ikegaya, 2005). Both hyperhomocysteinemia and renal injury are associated as pathogenic processes, creating a vicious cycle that results in further impairment of renal function.

\subsubsection{Cystatin-C}

Recently, Cystatin-C, a protein member of the family of cysteine proteinase inhibitors, was proposed as a new reliable marker of renal function. Because of its small size, cystatin $C$ is freely filtered by the glomerulus. It is not secreted but reabsorbed by tubular epithelial cells and subsequently catabolized so that it does not return to the blood flow (Abrahamson, 1990). It is the product of a gene expressed in all nucleated cells and is produced at a constant rate, therefore permitted calculation of a cystatin $C$ clearance using urine concentrations. Serum levels of cystatin $\mathrm{C}$ is a promising early marker of hypertensionassociated kidney dysfunction and may accurately reflect eGFR in various populations (Udani, 2011). The use of serum cystatin C to approximate eGFR is based on the same logic as the use of blood urea nitrogen and creatinine, but because it does not return to the bloodstream and is not secreted, the eGFR obtained may be more reflective of actual renal filtration function (McMurray, 2009). The cystatin C concentration is converted and reported in milliliters per minute giving a direct estimation of the GFR. Unlike serum creatinine, it is not influenced by age, sex, muscle mass, exercise or diet. A study from the Prevention of Renal and Vascular End-Stage Renal Disease (PREVEND) cohort found that cystatin C was significantly associated with C-reactive protein (CRP), smoking and body mass index, even after adjustment for creatinine clearance levels (Knight, 2004). The authors concluded that cystatin $C$ levels were influenced by these factors in addition to kidney function. Other longitudinal studies have shown that cystatin $C$ has a stronger and more linear association with cardiovascular disease and mortality outcomes compared to creatinine-based measures. These findings led to the hypothesis that cystatin C's link to inflammation could explain its advantage over creatinine as a prognostic marker (Singh, 2007).

\subsubsection{Advanced Glycation End Products (AGE)}

Advanced glycation end products (AGEs) are a heterogeneous group of proteins and lipids covalently bound to sugar residues. It appears that activation of the RAS may contribute to AGE formation through various mechanisms (Bohlender, 2005). Although AGEs could nonspecifically bind to basement membranes and modify their properties, they also induce specific cellular responses including the release of profibrogenic and proinflammatory cytokines by interacting with the receptor for AGE (Bohlender, 2005). AGE levels are grossly elevated in CKD and hemodialysis as a result of decreased clearance, resulting in an 
increased tissue accumulation. The accumulation of AGE in renal failure is even greater than in diabetes (Noordzij, 2008).

\subsubsection{Resistin}

Resistin, a newly discovered low molecular weight plasma protein, promotes endothelial dysfunction and proinflammatory activation, contributing to subclinical atherosclerosis (Dimitriadis, 2009). Although classified as an adipokine, resistin in humans is mainly produced by blood-derived leukocytes and mononuclear cells, both within and outside the adipose tissue (Ellington, 2007). Resistin directly induces endothelin-1 production, upregulates adhesion molecules and chemokines, and downregulates TNF receptorassociated factor-3 (Verma, 2003). Resistin-induced mitochondrial dysfunction and imbalance in cellular redox enzymes may be the underlying mechanisms of oxidative stress (Chen, 2010). The humoral factors induced by resistin and their downstream effectors could potentiate mesangial proliferation and interstitial fibrosis, thereby affecting both glomerular and tubular processes. Recently, elevated levels of resistin were proposed to be a risk factor for kidney disease or may even represent overt kidney damage in asymptomatic adults with essential hypertension (Ellington, 2007).

\subsubsection{Kidney injury molecule-1 (KIM-1)}

The kidney injury molecule-1 (designated as Kim-1 in rodents, KIM-1 in humans) mRNA was identified using techniques of representational difference analysis, a PCR-based technique (Hubank, 1994; Bonventre, 2009). KIM-1 is a type 1 transmembrane protein that is not detectable in normal kidney tissue but is expressed at high levels in human and rodent kidneys with dedifferentiated proximal tubule epithelial cells after ischemic or toxic injury (Han, 2005). KIM-1 is strongly up-regulated in dedifferentiated proximal tubule kidney epithelial cells after an ischemic or toxic injury. It may also play a role in epithelial adhesion, growth, and differentiation (Malyszko, 2010). KIM-1 not only functions as a biomarker but also has predictive value for acute renal injury, but was predictive for adverse clinical outcome in a cohort of 201 hospitalized patients with acute renal failure (Lock, 2010). Urinary Kim-1 levels may serve as a noninvasive, rapid, sensitive, reproducible, and potentially high-throughput method to detect early kidney injury in pathophysiological studies and in preclinical drug development studies for risk-benefit profiling of pharmaceutical agents (Vaidya, 2006).

\subsubsection{Asymmetric dimethylarginine}

Asymmetric dimethylarginine (ADMA) is a naturally occurring L-arginine analogue, found in plasma and various types of tissues, acting as an endogenous NO synthase inhibitor in vivo (Ueda, 2007). Further, plasma level of ADMA is elevated in patients with CKD and found to be a strong biomarker or predictor for future cardiovascular events (Ueda, 2007). In addition, plasma level of ADMA could predict the progression of renal injury in these patients, as well. These findings suggest that elevation of ADMA may be a missing link between CVD and CKD. ADMA levels are markedly elevated in renal impairment, together with the experimental evidence showing ADMA to be a CKD progression factor in animals; four prospective studies have found an association between ADMA level and CKD progression in humans (Kronenberg, 2009). 


\subsubsection{Interleukin-18 (IL-18)}

Interleukin-18 (IL-18) is a proinflammatory cytokine which is induced in PCT and is detected in urine following AKI. It was found to be an early predictor of AKI in patients with adult respiratory distress syndrome with an area under the curve (AUC) of 0.73 (Soni, 2009). It was also found to be an independent predictor of mortality in this study. In another study on patients undergoing cardiac surgery, urinary IL-18 levels increased $6 \mathrm{~h}$ after cardiopulmonary bypass (CPB) and peaked at $12 \mathrm{~h}$ in patients who were diagnosed to have AKI 2 days later by creatinine criteria (Han, 2009). Elevated urinary IL-18 is more specific for ischemic AKI and its levels are not deranged in CKD, urinary tract infections or nephrotoxic AKI. However, a study by Haase et al. did not find IL-18 to be a useful early predictor of AKI in a group of 100 adult patients undergoing cardiac surgery (Soni, 2009).

\subsubsection{Urinary Netrin-1 (Ntn-1)}

Netrin-1 (Ntn-1), a laminin-related axon guidance molecule, is highly induced and excreted in the urine after acute kidney injury (AKI) in animals (Ramesh, 2010). Previous studies proved that Ntn-1 is involved in the orchestration of inflammatory responses in vitro or in vivo (Ly, 2005; Rosenberger, 2009). The kidney has one of the highest levels of netrin-1 expression, and administration of recombinant netrin- 1 before ischemia reperfusion reduces kidney injury and inflammation (Wang, 2008).

\subsubsection{Urinary neutrophil gelatinase-associated lipocalin (NGAL)}

Urinary neutrophil gelatinase-associated lipocalin (NGAL) is a small (25 kDa) protein, expressed in renal tubular cells and released into the blood and urine after exposure to ischemia or toxicity (Devarajan, 2010) and represent a promising new renal biomarker able to diagnose acute kidney injury (AKI). It is rapidly induced and released from the injured renal distal nephrons in experimental studies and various human diseases. The changes of body water content could, thus, influence the urinary concentration, like for other urinary biomarkers, too. The release of NGAL occurs within hours after the stimulus and long before an increase in serum creatinine level. Urinary and plasma concentrations of NGAL increase proportionally to severity and duration of renal injury and rapidly decrease with its attenuation. However, NGAL release is not specific to the kidney. Measurements may be readily and easily performed in urine and plasma using clinical laboratory platforms or point of care devices (Haase, 2011). Therefore, the NGAL level was proposed to be a realtime indicator of active kidney damage, whereas creatinine level and GFR are markers of functional nephron number (Kronenberg, 2009).

\subsubsection{Liver-type fatty acid binding protein (L-FABP)}

Clinical data on associations between liver-type fatty acid binding protein (L-FaBP) and kidney disease are sparse (Kronenberg, 2009). This protein is expressed in proximal tubular cells and increased expression and higher levels are seen in the urine of patients with kidney disease and is considered a promising indicator of tubular but not glomerular damage (Kamijo-Ikemori, 2011). A large health screening program in more than 900 individuals revealed that average urinary levels of L-FaBP were approximately $50 \%$ higher in patients with diabetes mellitus, hypertension or chronic hepatitis than in controls. A study investigating L-FaBP levels in patients with type 2 diabetes and different stages of nephropathy showed that urinary L-FaBP was associated with the severity of diabetic 
nephropathy (Nakamura, 2005). Small studies in patients with mild kidney dysfunction suggest that urinary L-FaBP concentrations are increased in patients whose renal function deteriorates further (Kamijo, 2004).

\subsection{Lifestyle modifications}

In the general population, the strategies that lower blood pressure include dietary and lifestyle modifications in order to prevent and treat arterial hypertension. Blood pressure and CKD management rely heavily upon the patient's ability to self-manage and willingness to change or maintain health-promoting behaviors. The prevalence of hypertension may be also reduced also by measures like eight loss, sodium restriction, fluid restriction, exercise, and limitation of alcohol intake (Miller, 2003).

The Intersalt Cooperative Research Study, which measured urinary sodium in over 10,000 individuals from 32 countries, found that consumption of more than $100 \mathrm{mmol} /$ day sodium was associated with significantly higher blood pressures (Miller, 2003). Sodium restriction is also a crucial component to dietary intake for patients with CKD. In CKD, extracellular volume expansion as a result of impaired natriuresis is thought to play an important role in the pathogenesis of hypertension. It is therefore recommended that dietary sodium intake should be less than $100 \mathrm{mmol} /$ day. Exercise and weight loss (if body mass index is more than $25 \mathrm{~kg} / \mathrm{m}^{2}$ ) are also recommended (Thuraisingham, 2011).

The Dietary Approaches to Stop Hypertension (DASH) diet has been shown to produce most benefits in blood pressure reduction through sodium restriction and weight loss, and can also decrease LDL cholesterol. The DASH diet is a result of a feeding study of 459 adults (49\% women, $60 \%$ African American) with high normal or elevated blood pressure (Sacks, 2001).

\subsection{Pharmacologic intervention}

The discussed pathophysiology of hypertensive renal damage suggests three broad targets for therapeutic interventions: (1) reduction of BP load; (2) reduction of pressure transmission to the renal microvasculature; and (3) interruption and/or modification of the local cellular/molecular pathways that mediate eventual tissue injury and fibrosis (Bidani, 2004). Antihypertensive therapy significantly decreases the vascular damage in the kidneys of hypertensive patients. Therapy of hypertension is therefore imperative. The National Kidney Foundation clinical practice guidelines recommend a blood pressure goal of $<130$ $\mathrm{mmHg}$ systolic and $<80 \mathrm{mmHg}$ diastolic for all CKD patients. Post-hoc analyses of the Modification of Diet in Renal Disease study indicate that lower blood pressure may provide long-term kidney protection in patients with nondiabetic kidney disease. Specifically a mean arterial pressure < $92 \mathrm{mmHg}$ (e.g. 120/80 mmHg) compared to 102-107 mmHg (e.g. 140/90 $\mathrm{mmHg}$ ) is associated with a reduced risk for ESRD (Toto, 2005). Citing KDOQI, the seventh report from the Joint National Committee on Prevention, Detection, Evaluation, and Treatment of High Blood Pressure (JNC 7) also recommends a target BP of $<130 / 80 \mathrm{mmHg}$ for all patients with CKD defined as an GFR $<60 \mathrm{ml} / \mathrm{min}$ per $1.73 \mathrm{~m}^{2}$ or protein-to-creatinine ratio $\geq 200 \mathrm{mg} / \mathrm{g} .1 \mathrm{~A}$ target $\mathrm{BP}<130 / 80 \mathrm{mmHg}$ is also recommended by the American Diabetes Association (ADA) and by JNC 7 for all patients with diabetes (O'Hare, 2009).

The inhibition of the effects of angiotensin II is necessary to ensure the best degree of renal protection by the simultaneous control of blood pressure (BP) and the achievement of the maximal antiproteinuric capacity. The inhibition can be attained through the administration 
of either an angiotensin-converting enzyme (ACE) inhibitor or an angiotensin II receptor blocker (ARB). Uptitration of antihypertensive therapy is frequently required to achieve the desired BP goal in patients presenting with renal disease, with or without proteinuria. Control of BP is good for both cardiovascular and renal protection (Segura, 2003).

RAS inhibitors have been shown to reduce proteinuria and the rate of loss of renal function in patients with CKD (Ito, 2010). However, the benefits of RAS inhibition seem to depend on the degree of proteinuria at baseline. Namely, RAS inhibition has been shown to be beneficial in patients with at least $0.5 \mathrm{~g}$ per day proteinuria, whereas no convincing evidence exists to demonstrate the benefits extended to patients with a lower level of proteinuria (Jafal, 2001). An "adequate" BP control with standard antihypertensive therapy, the kidney is well protected and very few hypertensive patients, less than $2 \%$, will develop renal damage as a consequence of arterial hypertension (Ruilope, 2002). Interestingly, data from the ACCOMPLISH trial demonstrated that use of an ACE inhibitor in combination with a calcium antagonist was associated with a reduced requirement for dialysis than use of an ACE inhibitor and a diuretic in individuals $>65$ years of age (Backris, 2010).

Identifying individuals with early signs of CKD might help the targeting of therapies to more effectively prevent disease progression and associated complications. Identifying an appropriate marker of early renal dysfunction, however, remains challenging and depends on the underlying etiology of kidney disease. Early diagnosis on the basis of presence of proteinuria or reduced estimated GFR could permit early intervention to reduce the risks of cardiovascular events, kidney failure, and death that are associated with chronic kidney disease. In developed countries, screening for the disorder is most effective when targeted at high-risk groups including elderly people and those with concomitant illness (such as diabetes, hypertension, or cardiovascular disease) or a family history of chronic kidney disease, although the role of screening in developing countries is not yet clear. Different strategies available now aimed to slow the progression of CKD and to reduce cardiovascular risk (James, 2010). Treatment of high blood pressure is recommended for all individuals with, or at risk of, chronic kidney disease. Use of angiotensin-converting-enzyme inhibitors or angiotensin-receptor blockers is preferred for patients with diabetic CKD or those with the proteinuric non-diabetic disorder (Matthew, 2010).

\section{Conclusion}

In conclusion, hypertension-associated renal damage would paradoxically originate from subtle, focal renovascular damage, where hypertension would be another mere consequence acting as a magnifying amplifier in the vicious circle of malignancy. The therapeutic strategy aims, at targeting the pathophysiological processes mentioned in this chapter, to prevent, reduce or reverse the renal organ damage due to arterial hypertension.

\section{References}

Abrahamson, M.; Olafsson, I.; Palsdottir, A.; Ulvsback, M.; Lundwall, A. et al. (1990). Structure and expression of the human cystatin C gene. Biochemical Journal, Vol. 268, (June, 1990), pp. 287-294.

Agarwal. R. (2010). Epidemiology of chronic kidney disease among normotensives. But what is chronic kidney disease? Hypertension, Vol. 55. (May, 2010), pp. 1097-1099. 
Appel, L. J. et al. (2008). Long-term effects of renin-angiotensin system-blocking therapy and a low blood pressure goal on progression of hypertensive chronic kidney disease in African Americans. Archives of Internal Medicine, Vol. 168, (April, 2008), pp. 832-839.

Bakris, G. L. et al. (2010). Renal outcomes with different fixed-dose combination therapies in patients with hypertension at high-risk for cardiovascular events (ACCOMPLISH): a prespecified secondary analysis of a randomized clinical trial. Lancet, Vol. 375, (April, 2010), pp.1173-1181.

Barsoum, R.S. (2006). Chronic kidney disease in the developing world. New England Journal of Medicine, Vol. 354, (March, 2006), pp. 997-999.

Bohlender JM, Franke S, Stein G, Wolf G. (2005). Advanced glycation end products and the kidney. American Journal of Physiology Renal Physiology, Vol. 289, Vol.4, (October, 2005), pp. F645-F659.

Bonventre, J. V. (2009). Kidney injury molecule-1 (KIM-1): a urinary biomarker and much more. Nephrology, Dialisis, Transplantation, Vol. 24, No.11, (November, 2011), pp. 3265-3268.

Chappell, M.C. (2010). Angiotensin-converting enzyme 2 autoantibodies: further evidence for a role of the renin-angiotensin system in inflammation, Arthritis research and therapy, Vol.12, No.3, (June, 2010), pp.128.

Chen C, Jiang J, Lü JM, Chai H, Wang X, Lin PH, Yao Q. (2010). Resistin decreases expression of endothelial nitric oxide synthase through oxidative stress in human coronary artery endothelial cells. American Journal of Physiology Heart and Circulation Physiology, Vol. 299, No.1, (July, 2010), pp. H193-H201.

Cockcroft, D.W.; Gault, M.H. (1976). Prediction of creatinine clearance from serum creatinine. Nephron, Vol. 16, No.1. pp. 31-41.

Cohuet, G.; Struijker-Boudier, H. (2006). Mechanisms of target organ damage caused by hypertension: therapeutic potential. Pharmacology and Therapeutics, Vol. 111, (July, 2006), pp. 81-98.

Dalton, R.N., (2010). Serum creatinine and glomerular filtration rate: perception and reality. Clinical Chemistry, Vol. 56, (May, 2010), pp. 687-689.

Devarajan, P., (2010). Neutrophil gelatinase-associated lipocalin: a promising biomarker for human acute kidney injury. Biomarkers in Medicine, Vol. 4, No.2 (Aprilie, 2010), pp. 265-280.

Dimitriadis K, Tsioufis C, Selima M, Tsiachris D, Miliou A, Kasiakogias A et al. (2009). Independent association of circulating resistin with glomeular filtration rate in the early stages of essential hypertension. Journal of Human Hypertension, Vol.23, (May, 2009), pp. 668-673.

Dworkin, L.D; Shemin, D.G. (1999). The role of hypertension in progression of chronic renal disease. In: R.W. Schrier, Editor, Atlas of diseases of the kidneys, Current Medicine, Inc., Philadelphia (Pa) (1999), pp. 6.1-6.18.

Dwinnell, B.G.; Anderson, R.J. (1999). Diagnostic evaluation of the patient with acute renal failure, in Atlas of Diseases of Kidney, edited by Schrier RW, Philadelphia, Current Medicine Inc., 1999, pp 12.1-12.12.

Ellington, A.A.; Malik, A.R.; Klee, G.G.; Turner, S.T.; Rule, A.D.; Mosley TH Jr, Kullo IJ: (2007). Association of plasma resistin with glomerular filtration rate and albuminuria in hypertensive adults. Hypertension, Vol. 50, (October, 2007), pp. 708- 714.

Feig, D.I., Rang, D.H., Johnson, R.J. (2008). Uric acid and cardiovascular risk. New England Journal of Medicine, Vol. 359, (October, 2008), pp. 1811-1821.

Freedman, B.I. et al. (2009). Polymorphisms in the non-muscle myosin heavy chain 9 gene (MYH9) are strongly associated with end-stage renal disease historically attributed 
to hypertension in African Americans. Kidney International, Vol. 75, (April, 2009), pp. 736-745.

Gomez Campdera FJ, Luno J, Garcia de Vinuesa S, Valderrabano F. (1998). Renal vascular disease in the elderly. Kidney International, Vol. 68, (December, 1998), pp.S73-S77.

Griffin, K.A.; Abu-Amarah, I.; Picken, M.; Bidani, A.K. (2003), Renoprotection by ACE inhibition or aldosterone blockade is blood pressure-dependent. Hypertension, Vol. 41, (February, 2003), pp. 201-206.

Guyenet PG. (2006). The sympathetic control of blood pressure. Nature Review Neuroscience, Vol.7,(May, 2006), pp. 335-346.

Haase, M. (2011). NGAL - From discovery to a new era of "Acute Renal Disease" diagnosis? Clinical Biochemistry, Vol. 44, No. 7. (May 2011), pp. 499-500.

Han, WK et al. (2005). Human Kidney Injury Molecule-1 is a Tissue and Urinary Tumor Marker of Renal Cell Carcinoma, Journal of the American Society of Nephrology, Vol. 16, no. 4, (April, 2005), pp. 1126-1134.

Heymsfield, S.B.; Arteaga, C.; McManus, C.; Smith, J.; Moffitt, S. (1983). Measurement of muscle mass in humans: validity of the 24-hour urinary creatinine method. American Journal of Clinical Nutrition, Vol. 37, (March, 1983), pp. 478-494.

Hillege HL, Fidler V, Diercks GF, et al. (2002). Urinary albumin excretion predicts cardiovascular and noncardiovascular mortality in general population, Circulation, Vol. 106, (September, 2002), pp. 1777-1782.

Hoogeveen EK, Kostense PJ, Jager A et al. (1998). Serum homocysteine level and protein intake are related to risk of microalbuminuria: the Hoorn Study. Kidney International, Vol. 54, pp. 203-209.

Hsu CY, Chertow GM, Curhan GC. (2002). Methodological issues in studying the epidemiology of mild to moderate chronic renal insufficiency. Kidney International, Vol. 61, pp. 1567-1576.

Hubank M, Schatz DG. (1994). Identifying differences in mRNA expression by representational difference analysis of cDNA. Nucleic Acids Research, Vol. 22, No.25, (December, 1994), pp. 5640-5648.

Ikegaya N, Yanagisawa C, Kumagai H. (2005). Relationship between plasma homocysteine concentration and urinary markers of tubulointerstitial injury. Kidney International, Vol. 67, No.1, (January, 2005), pp. 375.

Iwano, M.; Neilson, E.G. (2004). Mechanisms of tubulointerstitial fibrosis. Current Opinion in Nephrology and Hypertension, Vol. 13, (May, 2004), pp. 279-284.

Ito S. (2010). Usefulness of RAS inhibition depends on baseline albuminuria. Nature Review Nephrology, Vol. 6, (January, 2010), pp. 10-11.

Jafar, T.H. et al. (2001). Angiotensin-converting enzyme inhibitors and progression of nondiabetic renal disease. A meta-analysis of patient-level data. Annals of Internal Medicine, Vol. 135, (July, 2001), pp. 73-87.

Jamerson KA, Bakris GL, Wun C-C, et al. (2004). Rationale and design of the Avoiding Cardiovascular events through COMbination therapy in Patients LIving with Systolic Hypertension (ACCOMPLISH) trial. American Journal of Hypertension, Vol. 17, No.9, (September, 2004), pp. 793-801.

James, M.T.; Hemmelgarn, B.R.; Tonelli, M. (2010). Early recognition and prevention of chronic kidney disease. Lancet, Vol. 375. No. 9722, (April, 2010), pp. 1296-1309.

Johnson RJ, Segal MS, Srinivas T, Ejaz A, Mu W, Roncal C, Sanchez- Lozada LG, Gersch M, Rodriguez-Iturbe, B.; Kang, D.H.; Acosta, J.H. (2005). Essential hypertension, 
progressive renal disease, and uric acid: A pathogenetic link? Journal of the American Society of Nephrology, Vol. 16, (April, 2005), pp. 1909-1919.

Kamijo, A. et al. Urinary fatty acid-binding protein as a new clinical marker of the progression of chronic renal disease. The Journal of the Laboratory and Clinical Medicine, Vol. 143, No.1 (January, 2004), pp. 23-30 (2004).

Kamijo, A. et al. (2006). Urinary liver-type fatty acid binding protein as a useful biomarker in chronic kidney disease. Molecular and Cellular Biochemistry, Vol. 284, No.1-2, (March, 2006), pp. 175-182.

Kamijo-Ikemori A, Sugaya T, Yasuda T et al. (2011). Clinical significance of urinary livertype fatty acid binding protein in diabetic nephroptahy of type 2 diabetic patients. Diabetes Care, Vol. 34, (July, 2011), pp. 691-696.

Kang DH, Nakagawa T, Feng L, Watanabe S, Han L, Mazzali M, et al. (2002). A role of uric acid in the progression of renal disease. Journal of the American Society of Nephrology, Vol. 13, (December, 2002), pp. 2888-2897.

Komlosi P, Fuson AL, Fintha A, Peti-Peterdi J, Rosivall L, Warnock DG, Bell PD. (2003) Angiotensin I conversion to angiotensin II stimulates cortical collecting duct sodium transport. Hypertension, Vol. 42, (August, 2003), pp.195-199.

Kobori H, Nangaku M, Navar LG, Nishiyama A. (2007), The intrarenal renin-angiotensin system: from physiology to the pathobiology of hypertension and kidney disease. Pharmacological reviews, Vol. 59, (September, 2007), pp. 251-287.

Kobori H, Urushihara M, Xu JH, Berenson GS, Navar LG. (2010). Urinary angiotensinogen is correlated with blood pressure in men (Bogalusa Heart Study). Journal of Hypertension, Vol. 28, (July, 2010), pp. 1422-1428.

Kronenberg, F. (2009). Emerging risk factors and markers of chronic kidney disease progression. Nature Reviews Nephrology, Vol. 5. (December, 2009) pp. 677-689.

Lee JE, Kim YG, Choi YH, Huh W, Kim DJ, Oh HY. (2006). Serum uric acid is associated with microalbuminuria in prehypertension. Hypertension, Vol. 47, (March, 2006), pp. 962-967.

Leemans JC, Butter LM, Pulskens WP, Teske GJ, Claessen N, et al. (2009). The role of Tolllike receptor 2 in inflammation and fibrosis during progressive renal injury. Public Library of Science ONE, Vol. 4. No.5, (May, 2009), pp. e5704.

Levey, A.S.; Coresh, J.; Greene, T.; Marsh, J.; Stevens, L.A.; Kusek, J.W.; Van Lente, F. (2007). Expressing the modification of diet in renal disease study equation for estimating glomerular filtration rate with standardized serum creatinine values. Clinical Chemistry, Vol. 53, (March, 2007), pp. 766-772.

Ljutic, D.; Kes, P. (2003). The role of arterial hypertension in the progression of non-diabetic glomerular diseases. Nephrology Dialysis Transplantation, Vol. 18. (July, 2003), Pp. v28-v30.

Locatelli, F.; Vecchio, L.D.; Pozzoni, P. (2002). The importance of early detection of chronic kidney disease, Nephrology Dialysis Transplantation, Vol. 17, Suppl. 11, pp. 2-7.

Lock, E.A. (2010). Sensitive and early markers of renal injury: where are we and what is the way forward? Toxicology Sciences, Vol. 116. No.1, (July, 2010), pp. 1-4.

Lockhart, C.J.; Hamilton, P.K.; Quinn, C.E.; McVeigh, G.E. (2009). End-organ dysfunction and cardiovascular outcomes: The role of the microcirculation. Clinical Science, Vol. 116, (February, 2009), pp. 175-190.

López-Novoa et al. (2011). Etiopathology of chronic tubular, glomerular and renovascular nephropathies: Clinical implications, Journal of Translational Medicine, Vol. 9, (January, 2011), pp. 13. 
Ly NP, Komatsuzaki K, Fraser IP, Tseng AA, Prodhan P, et al. (2005) Netrin-1 inhibits leukocyte migration in vitro and in vivo. Proceedings of the National Academy of Science of the United States of America, Vol. 102, No.41, (October, 2005), pp. 14729- 14734.

Mai, M.; Geiger, H.; Hilgers, K.F. et al. (1993). Early interstitial changes in hypertensioninduced renal injury. Hypertension, Vol. 22, (November, 1993), pp. 754-765.

Malyszko J, Koc-Zorawska E, Malyszko JS, Mysliwiec M. (2010). Kidney injury molecule-1 correlates with kidney function in renal allograft recipients. Transplant Proceedings, Vol. 42, No.10, (December, 2010), pp. 3957-3959.

Mancia G, De Backer G, Dominiczak A, Cifkova R, Fagard R, et al. (2007). The Task Force for the Management of Arterial Hypertension of the European Society of Hypertension (ESH) and of the European Society of Cardiology (ESC). European Heart Journal, vol. 28, No.12, (June, 2007), pp. 1462-1536.

Marangella, M. (2005). Uric acid elimination in the urine. Pathophysiological implications. Contributions to Nephrology, Vol. 147, pp. 132-148, DOI: 10.1159/000082551.

Marín R, Gorostidi M, Fernández-Vega F, Alvarez-Navascués R. (2005). Systemic and glomerular hypertension and progression of chronic renal disease: the dilemma of nephrosclerosis. Kidney International, vol.99, (December, 2005), pp. 52-56.

Marney, A.M.; Brown, N.J. (2007). Aldosterone and end-organ damage. Clinical Sciences (Lond). Vol. 113, (August, 2007), pp. 267-78.

Mattson Porth C. (2011). Essentials of Pathophysiology, 3rd Edition, Wolters Kluwer Health, Lippincott Williams \& Wilkins, Philadelphia.

McMurray, M.D.; Trivax, J.E.; McCullough, P.A. (2009). Serum cystatin C, renal filtration function, and left ventricular remodeling, Circulation. Heart failure, vol. 2, no. 2, (March, 2009), pp. 86-89.

Mishra, J.; Dent, C.; Tarabishi, R.; et al. (2005). Neutrophil gelatinase-associated lipocalin (NGAL) as a biomarker for acute renal injury after cardiac surgery. Lancet, Vol. 365, pp. 1231-1238.

Mitchell KD, Braam B, Navar LG (1992). Hypertension mechanisms mediated by the renal actions of the renin-angiotensin system, Hypertension, Vol. 19, Suppl I, pp. I18-I27.

Montañés BR, Gràcia GS, Pérez SD, Martínez CA, Bover SJ. (2011). Consensus document. Recommendations on assessing proteinuria during the diagnosis and follow-up of chronic kidney disease, Nefrologia, (May, 2011), Vol. 31, No.3, pp. 331-45.

Nakamura T, Sugaya T, Kawagoe Y, Ueda Y, Osada S, Koide H. (2005). Effect of pitavastatin on urinary liver-type fatty acid-binding protein levels in patients with early diabetic nephropathy. Diabetes Care, Vol. 28, No.11, (November, 2005), pp. 2728- 2732.

National Kidney Foundation. (2002). K/DOQI clinical practice guidelines for chronic kidney disease: evaluation, classification, and stratification. American Journal of Kidney Diseases, Vol. 392, suppl 1, (February, 2002), pp. S1-266.

Navar LG and Hamm LL. (1999). The kidney in blood pressure regulation. In: Atlas of Diseases of the Kidney. Hypertension and the Kidney, edited by Wilcox CS. Philadelphia: Current Medicine, Inc., 1999, p. 1.1-1.22.

Navar LG, Harrison-Bernard LM, Nishiyama A, Kobori H. (2002). Regulation of intrarenal angiotensin II in hypertension. Hypertension. Vol. 39, pp. 316-322.

Nagakawa T, Kang DH, Feig D, Sanchez-Lozada LG, Srinivas TR, Sautin Y, Ejaz AA, Segal M, Johnson RJ. (2006). Unearthing uric acid: An ancient factor with recently found significance in renal and cardiovascular disease. Kidney International, Vol. 69, No.10. (May, 2006), pp. 1722-1725. 
Noordzij, M.J.; Lefrandt, J.D.; Smit, A.J. (2008). Advanced glycation end products in renal failure: an overview, Journal of Renal Care, Vol. 34, No.4. (November, 2008), pp. 207- 212.

Plantinga, L.C.; Tuot, D.S.; Powe, N.R. (2010). Awareness of chronic kidney disease among patients and providers. Advances in Chronic Kidney Disease, Vol. 17. No.3, (May, 2010), pp. 225- 236.

Perticone, F., Maio, R., Perticone, M., Sciacqua, A., Shehaj, E., Naccarato, P. and Sesti, G. (2010). Endothelial dysfunction and subsequent decline in glomerular filtration rate in hypertensive patients. Circulation, Vol. 122, No.4, (July, 2010), pp. 379-384.

Pohl, M.A. (1999). Renovascular hypertension and ischemic nephropathy. Atlas of Diseases of the Kidney, 1st Ed., edited by Wilcox CS, Schrier RW, Philadelphia, Current Medicine, pp. 3.1-3.21.

Post TW, Rose BD. (2006). Urinalysis in the diagnosis of renal disease. Up To Date, Vol. 13, pp. 3.

Prunotto, M.; Gabbiani, G.; Pomposiello, S.; Ghiggeri, G., Moll, S. (2011). The kidney as a target organ in pharmaceutical research. Drug Discovery Today, Vol. 16. No. 5-6, (March 2011), pp. 244-259.

Ramesh G, Krawczeski CD, Woo JG, Wang Y, Devarajan P. (2010). Urinary netrin-1 is an early predictive biomarker of acute kidney injury after cardiac surgery. Clinical Journal of American Society of Nephrology, Vol. 5, No.3 (March, 2010), pp. 395-401.

Redon J, Rovira E, Miralles A, Julve R, Pascual JM. (2002). Factors related to the occurrence of microalbuminuria during antihypertensive treatment in essential hypertension. Hypertension, Vol. 39, No.3, (March, 2002), pp. 794-798.

Roldán, J.; Morillas, P.; Castillo, J; Andrade, H; Guillén S. (2010). Plasma aldosterone and glomerular filtration in hypertensive patients with preserved renal function, Revista Española de Cardiología (English Edition), Vol. 63. No.1, (January, 2010), pp. 103-106.

Romero JC and Reckelhoff JF. (1999). Role of angiotensin and oxidative stress in arterial hypertension. Hypertension, Vol. 34:, pp. 943-949.

Rosenberger P, Schwab JM, Mirakaj V, Masekowsky E, Mager A, et al. (2009) Hypoxiainducible factor-dependent induction of netrin-1 dampens inflammation caused by hypoxia. Nature Immunology, Vol. 10, No.2, (February, 2009), pp. 195-202.

Ruilope, L.M. (2002). The kidney as a sensor of cardiovascular risk in essential hypertension. Journal of the American Society of Nephrology, Vol. 13, Suppl. 3, (November, 2002), pp. S165- S168.

Sacks FM, Svetkey LP, Vollmer WM, Appel LJ, Bray GA, Harsha D, et al. (2001). Effects on blood pressure of reduced dietary sodium and the Dietary Approaches to Stop Hypertension (DASH) diet. DASH-Sodium Collaborative Research Group. New England Journal of Medicine, (January, 2001), Vol. 344 , pp. 3-10.

Segura, J.; Christiansen, H.; Campo, C; Ruilope, L.M. (2003). How to titrate ACE inhibitors and angiotensin receptor blockers in renal patients: According to blood pressure or proteinuria? Current Hypertension Reports, Vol. 5, (October, 2003), pp. 426-429.

Singh, D.; Whooley, M.A.; Ix JH, Ali, S, Shlipak MG. (2007). Association of cystatin C and estimated GFR with inflammatory biomarkers: The Heart and Soul Study. Nephrology Dialisis Transplant, Vol. 22, (January, 2007), pp. 1087-1092.

Soni, S.S.; Ronco, C.; Katz, N.; Cruz, D.N. (2009). Early diagnosis of acute kidney injury: the promise of novel biomarkers. Blood Purification, Vol. 28, No.3., (July, 2009), pp. 165- 174.

Staples, A.; Wong, C.S.; (2010). Risk factors for progression of chronic kidney disease. Current Opinion in Pediatrics, Vol. 22, No. 2, (April, 2011), pp. 161-169. 
Stuveling, E.M.; Hillege, H.L.; Bakker, S.J.; Gans, R.O.; De Jong, P.E.; De Zeeuw, D. (2003). Creactive protein is associated with renal function abnormalities in a nondiabetic population. Kidney International, Vol. 63, (February, 2003), pp. 654-661.

Stuveling, E.M.; Bakker, S.J.; Hillege, H.L.; de Jong, P.E.; Gans, R.O.B., de Zeeuw, D. (2005) Biochemical risk markers: a novel area for better prediction of renal risk? Nephrology Dialisis Transplantation, Vol. 20, No.3. (Mars, 2005), pp. 497-508.

Taal, M.W.; Brenner, B.M. (2006). Predicting initiation and progression of chronic kidney disease: developing renal risk scores. Kidney International, Vol. 70, No. 10, (September, 2006), pp. 1694-1705.

Tesch, G.H., et al. (2010). Review: Serum and urine biomarkers of kidney disease: A pathophysiological perspective. Nephrology, Vol. 15, (August, 2010), pp. 609-616.

Tikellis C, Bernardi S, Burns WC (2011) Angiotensin-converting enzyme 2 is a key modulator of the renin-angiotensin system in cardiovascular and renal disease. Current Opinion in Nephrology and Hypertension, Vol. 20, No.1, (January, 2011), pp. 62-68.

Toto, R.D. (2005). Treatment of hypertension in chronic kidney disease. Seminars in Nephrology, Vol. 25, No. 6, (November 2005), pp. 435-439.

Ueda S, Yamagishi S, Kaida Y et al. (2007). Asymmetric dimethylarginine may be a missing link between cardiovascular disease and chronic kidney disease. Nephrology (Carlton), Vol. 12, No.6, (December, 2007), pp. 582-590.

Udani, S.; Lazich, I.; Bakris, G.L. (2011). Epidemiology of hypertensive kidney disease.Nature Reviews Nephroogy. Vol. 7, (January, 2011), pp. 11-21.

Vaidya VS, Ramirez V, Ichimura T, Bobadilla NA, Bonventre JV. (2006). Urinary kidney injury molecule-1: a sensitive quantitative biomarker for early detection of kidney tubular injury. American Journal of Physiology Renal Physiology, Vol. 290, (February, 2006), pp. F517-29.

van Guldener C. (2006). Why is homocysteine elevated in renal failure and what can be expected from homocysteine-lowering? Nephrology Dialisis Transplant, Vol. 21, No.5, (May, 2006), pp.1161-1166.

Vasan R, Evans JC, Larson MG, Wilson PWF, Meigs JB, Rifai N, Benjamin EJ, Ledy D. (2004). Serum aldosterone and the incidence of hypertension in nonhypertensive persons. New England Journal of Medicine, Vol. 351, (July, 2004), No.1, pp. 333-341.

Verma S, Li SH, Wang CH, Fedak PW, Li RK, Weisel RD, Mickle DA. (2003). Resistin promotes endothelial cell activation: further evidence of adipokine-endothelial interaction. Circulation, Vol. 108, No.6, (July, 2003). pp.736-740.

Wang W, Reeves WB, Ramesh G. Netrin-1 and kidney injury. I. (2008). Netrin-1 protected against ischemia-reperfusion injury of the kidney. American Journal of Physiology Renal Physiology, Vol. 294, No.4, (April, 2008), pp. F739-47.

Weiner, D.E.; Tighiouart, H.; Elsayed, E.F.; Griffith, J.L.; Salem, D.N.; Levey, A.S. (2008). Uric acid and incident kidney disease in the community. Journal of American Society of Nephrology, Vo. 19, (March, 2008), pp. 1204-1211.

Welch GN, Loscalzo J. (1998). Homocysteine and atherothrombosis. New England Journal of Medicine, Vol. 338, No.15, (Aprilie, 1998), pp. 1042-1050 


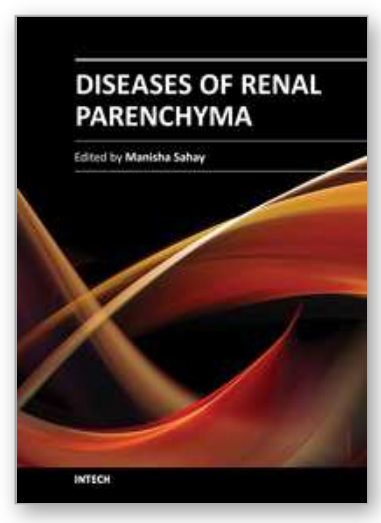

\author{
Diseases of Renal Parenchyma \\ Edited by Prof. Manisha Sahay
}

ISBN 978-953-51-0245-8

Hard cover, 304 pages

Publisher InTech

Published online 16, March, 2012

Published in print edition March, 2012

Clinical nephrology is an evolving speciality in which the amount of information is growing daily. This book gives quick access to some important clinical conditions encountered in nephrology including the diseases of glomeruli, tubules and interstitium. It presents the latest information on pathophysiology, diagnosis and management of important diseases of renal parenchyma. The information is presented in a very user friendly and accessible manner while the treatment algorithms enable the reader to quickly access expert advice on arriving at the most appropriate treatment regimen. The book discusses the renal involvement in various systemic diseases including diabetes and autoimmune diseases. Diabetic nephropathy is fast becoming the commonest cause of end stage renal disease all over the globe and is discussed in this book. The editors believe that this book will be a valuable addition to the reader's library.

\title{
How to reference
}

In order to correctly reference this scholarly work, feel free to copy and paste the following:

Corina Şerban, Rodica Mihăescu, Lavinia Noveanu, loana Mozoş, Ruxandra Christodorescu and Simona Drăgan (2012). Arterial Hypertension and Renal Disease, Diseases of Renal Parenchyma, Prof. Manisha Sahay (Ed.), ISBN: 978-953-51-0245-8, InTech, Available from: http://www.intechopen.com/books/diseases-ofrenal-parenchyma/arterial-hypertension-and-renal-disease

\section{INTECH}

open science | open minds

\author{
InTech Europe \\ University Campus STeP Ri \\ Slavka Krautzeka 83/A \\ 51000 Rijeka, Croatia \\ Phone: +385 (51) 770447 \\ Fax: +385 (51) 686166 \\ www.intechopen.com
}

\author{
InTech China \\ Unit 405, Office Block, Hotel Equatorial Shanghai \\ No.65, Yan An Road (West), Shanghai, 200040, China \\ 中国上海市延安西路65号上海国际贵都大饭店办公楼 405 单元 \\ Phone: +86-21-62489820 \\ Fax: +86-21-62489821
}


(C) 2012 The Author(s). Licensee IntechOpen. This is an open access article distributed under the terms of the Creative Commons Attribution 3.0 License, which permits unrestricted use, distribution, and reproduction in any medium, provided the original work is properly cited. 